\title{
Prevalence and correlates of psychological distress in a large and diverse public sector workforce: baseline results from Partnering Healthy@Work
}

\author{
Lisa Jarman ${ }^{1 *}$, Angela Martin ${ }^{2}$, Alison Venn ${ }^{1}$, Petr Otahal ${ }^{1}$, Roscoe Taylor ${ }^{3}$, Brook Teale $^{4}$ and Kristy Sanderson ${ }^{1}$
}

\begin{abstract}
Background: Depressive and anxiety disorders are common among working adults and costly to employers and individuals. Mental health screening is often an important initial strategy, but the resultant data are often of unknown representativeness and difficult to interpret. In a public sector workforce, this study used a brief screener for depression/anxiety to: a) compare prevalence of high psychological distress obtained from a researcher survey with an employer survey and population norms and b) verify whether expected correlates were observed in a screening setting.
\end{abstract}

Methods: Participants were public servants working for an Australian state government. High psychological distress (Kessler-10 222) stratified by age and sex was compared for a random weighted sample researcher survey $(n=3406)$ and an anonymous volunteer employer survey $(n=7715)$. Prevalence ratios (PR) were estimated from log binomial regression.

Results: Referencing the researcher survey, prevalence of high psychological distress was greater by age and sex in the employer survey but was only dependably higher for men when compared with population norms. Modelling suggested this may be due to work stress (effort-reward imbalance) $(\mathrm{PR}=3.19,95 \% \mathrm{Cl} 1.45-7.01)$ and casual/fixed-term employment (PR 2.64, 95\% Cl 1.26-5.56).

Conclusions: Depression and anxiety screening using typical employer survey methods could overestimate prevalence but expected correlates are observed in a screening setting. Guidance for employers on screening and interpretation should be provided to encourage engagement with mental health prevention and treatment programs in the workplace.

Keywords: Prevalence, Correlates, Workplace, K10, Public sector, Health risk appraisal, Psychological distress

\section{Background}

The common mental disorders of depression and anxiety are among the greatest public health challenges of this era [1]. The earlier issues such as workplace depression are accurately identified and treated, the sooner improvements in work outcomes are likely to occur [2]. As a result, understanding the nature of workplacebased risks associated with poor mental health and addressing these risk factors has been an area of considerable research and practice interest. Researchers have

\footnotetext{
* Correspondence: lisa.jarman@utas.edu.au

${ }^{1}$ Menzies Research Institute Tasmania, University of Tasmania, Hobart, Tasmania, Australia

Full list of author information is available at the end of the article
}

argued that employers should become involved in workforce screening of mental health because the data obtained can assist the development of relevant workplace interventions [3].

Despite the need for workplace action on issues such as depression, transfer of mental health screening into the hands of an employer has specific barriers and challenges [4]. First, employers are typically interested in feedback systems that enable sound management decisions. However, employer surveys are usually anonymous and have volunteer samples [5] that can affect the validity and generalizability of findings.

Second, mental health screening using Health Risk Appraisals (HRAs) has evolved from individually focused,

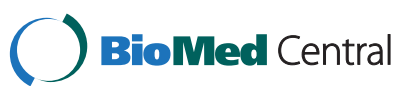


clinical settings [5] rather than work environments. Although there is some evidence supporting the use of HRAs in physical health promotion at work [6] there seems to be a gap in published information on the results obtained by employers who use mental health or associated measures. For example, despite the efforts that Great Britain's Health and Safety Executive (HSE) has made to develop a viable measure of psychosocial safety, a recent study reported that employers were not using the HSE Indicator Tool as recommended (i.e. used abridged versions, applied only once, substituted with other measures) [7].

Third, employers are realistically concerned about the legal implications of identifying mental health conditions in the workplace [8]. Therefore, to encourage engagement in mental health screening researchers have a role in educating employers about how to interpret findings in view of: a) the limitations of the screening methods and measures used: and b) the expected ranges given the demographic profile of their workforce.

A key population of interest for mental health screening is the public sector (also referred to as the state or government sector), whose employees appear to be vulnerable to poor mental health [3,9]. Given the large number of employees impacted internationally, accurate monitoring of the mental health of public sector employees seems to be an important consideration for public health.

The mental health status of public sector workforces has been researched for several decades (e.g. Whitehall [10], WORC [3]) and has coincided with the implementation of New Public Management (NPM) organisational concepts within civil services around the world. These reforms have led to a wide range of changes to the traditional roles of government and its associated management structures. Reforms have typically included the introduction of private sector concepts such as outsourcing, rationalization, decentralization and performance orientation [11].

There has been considerable debate as to whether organisational change has a negative impact on these employees [12], but evidence from public service populations has reported increased job strain [13], increased presenteeism [14] and sick leave [15], and decreased organisational commitment [13]. Public sector employees have been found to report higher levels of psychological distress than their private sector counterparts [16,17]. However, we do not know if these purported higher levels are a consequence of the different survey methods used, or are due to actual differences in distress in these working populations. In the absence of clarity on these issues, interpretation of whether a public sector result is 'high' or not can be furthered by making comparison with working population norms for psychological distress. We acknowledge that population norms can underestimate the prevalence of poor mental health due to non-response bias [18] and as a result comparisons are imperfect. Despite their limitations, these norms can act as a third 'best estimate' of prevalence where organisational data are contradictory.

One validated way of assessing risk for depressive and anxiety disorders is the Kessler 10 (K10) brief screening scale [19]. This 10-item scale measures 'psychological distress' and has acceptable performance as a screener for DSM-IV depressive and anxiety disorders [20]. Although the K10 can be used to assess the prevalence of psychological distress in workers, it gives no clues about modifiable risk factors influencing poor mental health. When the K10 is applied in a HRA context, it is important to assess whether high distress is associated with the typical demographic, socio-economic, health, and work correlates found in other literature [10]. If the K10 correlates with expected characteristics this result adds evidence of validity to the application of the K10 for detecting high distress in public sector employees.

In this study, results obtained from random weighted and anonymous volunteer HRA surveys using the K10 were compared within a large and diverse public sector organisation. We wanted to assess whether the prevalence of high psychological distress was greater than that of working population norms and verify that the K10 results were associated with expected correlates in a screening setting.

Using a researcher survey as the reference, the aims of this study were to: a) compare the self-reported prevalence of psychological distress measured with a brief screener with that of an employer survey; b) determine whether prevalence differed to normative population data; and c) investigate and classify the socio-demographic, health and work correlates of self-reported high psychological distress.

\section{Method \\ Setting}

This study was based in Tasmania, which is an island State of Australia with a population of approximately 500,000 people. The setting for this research was in the form of a partnership, 'Partnering Healthy@Work' (PH@W), between the Tasmanian Government and the University of Tasmania. The Tasmanian State Service (TSS) is one of the region's largest employers with approximately 30,000 employees and incorporates a wide range of government departments (e.g. health, education, environment), occupations and locations (city-based, rural, remote). Since 2009, the Tasmanian Government has invested more than $\$ 2$ million in workplace health promotion, the "Healthy@Work" (H@W) initiative, targeting their whole workforce. Ethics approval for the study was obtained from the Human Research Ethics Committee (Tasmania) Network (ID: H0010501). 


\section{Study design}

Partnering Healthy@Work is a longitudinal evaluation of $\mathrm{H} @ \mathrm{~W}$ that includes collection and assembly of data from a range of data sources: a repeated, randomlyselected cross-sectional health workforce survey initiated by researchers (PH@W 2010 and 2013); an anonymous online employer-initiated workforce health survey (H@W 2009 and 2011); and human resource administrative data. This study used data from the first employer (H@W 2009) and researcher (PH@W 2010) workforce surveys, comparing it to normative prevalence data for the Australian and Tasmanian working populations.

\section{Public sector workforce data sources}

The researcher survey was distributed in February 2010 to TSS employees. We selected a 40\% random population sample from the total pool of employees, stratified according to employment condition, employment category and agency. The response rate was $28 \%$ $(\mathrm{N}=3406)$.

Survey responses were merged with an extract of administrative data from the TSS human resources database to permit analyses according to the key demographic variables of age, sex, employment condition (permanent, fixed-term or casual), employment category (full-time, part-time), annual salary, job classification ((Bands 1-3 [low], Bands 4-6 [mid], Bands 7-8 [high/ manager], Bands 9-10 [very high/ senior executive]), industrial award (blue collar, white collar, service, professional, manager), tenure (within the TSS, by government department) and public sector agency.

Standard survey weighting for the researcher survey was not possible due to very low response rates and zero cells in several strata. Therefore, to adjust for possible response bias, we applied the inverse probability of response weighting method described by Hofler and colleagues [21] based on a model including age, sex, government department, employment category, employment condition, and tenure using the human resources database as the reference population.

The employer survey was made available in an intranet-based format in 2009 to all TSS employees. It was designed by the TSS using a range of pre-existing measures and had a response rate of $25 \%(\mathrm{~N}=7715)$. This survey asked about age, sex, psychological distress (K10) and a range of lifestyle factors and behaviours that increase the chance of developing chronic health conditions like cardiovascular disease and diabetes. Distinct from the researcher survey, it did not: a) measure broader socio-demographic information, work contextual factors or psychosocial variables; b) use random selection or population stratification procedures; and c) it was anonymous so responses could not be matched to human resources data.

\section{Comparative normative data sources}

We collated population normative data for workers with the same K10 measure of psychological distress from two Australian cross-sectional datasets: a national mental disorder prevalence survey, the National Survey of Mental Health and Well-Being (NSMHWB) [22], and the Tasmanian Population Health Survey 2009 (TPHS) [23] (Table 1). The NSMHWB had a $60 \%$ response rate ( $\mathrm{N}=7715$ workers). Weighted survey respondent characteristics indicated $50 \%$ were female, $57 \%$ were married/ Defacto and $37 \%$ were in the 35 to 54 years age-range. The TPHS had a $70 \%$ response rate $(\mathrm{N}=3160$ workers $)$ and weighted characteristics showed $57 \%$ were female, $71 \%$ were married/ Defacto and 56\% were in the 35-54 years age range. Data were extracted by age, sex, employment status (i.e. workers) and psychological distress.

\section{Measures}

All of the surveys sought information on employed individuals' age and sex as well as psychological distress using the Kessler-10 (K10) screening scale which scores in a range of 10 to $50[19,20]$. The K10 total psychological distress score was categorized as low (10-21) versus high (22-50) [24]. A high ( $\geq 22)$ or very high score $(>29)$ gives a strong indication of a clinically diagnosable mental health condition [19].

The researcher survey measures, which were used to establish the correlates of psychological distress, included marital status (married or Defacto, not married); education level (up to year 10, up to year 12, post school); general physical health as measured by the SF-12 physical component summary scale [25]; smoking habits (daily smoker, all others) [26]; fruit and vegetable intake (inadequate, adequate) [27]; height and weight to measure body mass index (BMI); alcohol intake [28] (high risk, low risk) measured using national guidelines [29]; and total physical activity (minutes per week) derived from the Long International Physical Activity Questionnaire (IPAQ) [30].

Preferred work hours and contractual work characteristics included days worked (Monday to Friday, days vary weekly, other), schedule worked (regular days, other), and hours worked. Other psychosocial factors were measured using the Effort Reward Imbalance (ERI) questionnaire, which is a commonly applied validated self-report survey with 6 items measuring Effort and 11 items dedicated to Reward. A ratio is calculated for every person by first adding all scores for each of the effort $(e)$ and reward $(r)$ scales, then applying the formula $e /(r \times c)$ where $c$ equals the proportion 6/11 [31]. ERI ratio scores $\geq 1$ are argued to indicate an imbalance of high effort and low reward conditions.

\section{Statistical analysis}

We first derived the prevalence of high psychological distress as proportions of participants with K10 scores of 
Table 1 Data sources to compare employee psychological distress (Kessler 10)

\begin{tabular}{|c|c|c|c|c|c|}
\hline Survey & Type & Population & Participation rate & $\mathbf{n}$ & Method \\
\hline PH@W 2010¹ & Researcher-initiated & $\mathrm{TSS}^{5}$ employees & $28 \%$ & 3406 & Random weighted paper and pencil \\
\hline H@W 2009² & Employer-initiated & TSS employees & $25 \%$ & 7715 & Non-random anonymous online \\
\hline TPHS $2009^{3}$ & Population normative & Tasmanian working adults & $70 \%$ & 3160 & Random weighted telephone \\
\hline NSMHWB $2007^{4}$ & Population normative & Australian working adults & $60 \%$ & 5499 & Random weighted face-to-face \\
\hline
\end{tabular}

${ }^{1}$ Partnering Healthy@Work.

${ }^{2}$ Healthy@Work.

${ }^{3}$ Tasmanian Population Health Survey.

${ }^{4}$ National Survey of Mental Health and Well-Being.

${ }^{5}$ Tasmanian State Service.

22 or greater by age and sex in the researcher and employer surveys and the two population normative datasets, using the researcher survey as the reference to calculate variance estimates. The differences between proportions were assessed by calculating standard errors using the standard normal approximation for large samples, and assumed independent sampling. Analysis was stratified by sex. This approach was taken on theoretical grounds [32,33] because of known differences between men and women in correlates of psychological distress.

Second, we used the researcher survey data for multivariable model building [34] with dichotomized psychological distress as the outcome variable. We conducted a univariable analysis, and selected those variables with a p-value less than 0.25 for further analysis. Then we performed logistic regression analyses, entering the selected variables one at a time and conducting a Wald test upon each new variable's entry to determine if that variable significantly $(\mathrm{p}<0.05)$ increased model discrimination. This process selected the set of variables that provided the best discrimination between low and high psychological distress. ROC values of greater than 0.7 and less than 0.8 model 'acceptable discrimination' [34].

Separated by sex, individual covariates were entered one at a time in order of demographic (age, marital status), socio-economic (annual salary, education, occupation), contractual work characteristics (employment condition, employment category, tenure, hours worked, days worked, job classification, schedule worked), health behaviours (general physical health, inadequate fruit and vegetable intake, daily smoker, high risk alcohol, BMI, total physical activity) and psychosocial work environment (preferred hours, ERI). These classification processes did not permit data weighting procedures, so when these analyses were complete, the final sets of variables were used to build log binomial regression models by sex of the predictors of high psychological distress for estimation of weighted prevalence ratios (PR) [35]. All analyses were conducted using STATA 12.1 (StataCorp LP, Texas, USA).

\section{Results}

\section{Prevalence of high psychological distress}

The prevalence estimates of high psychological distress in the two Tasmanian State Service (TSS) workforce surveys are shown in Table 2 , stratified by age and sex. The results show that the employer survey estimates of prevalence of psychological distress for were statistically different $(p<0.001)$ to those of the researcher survey for both men (5.9\% higher) and women (6.4\% higher).

Using the same reference, high psychological distress totals were lower for male Tasmanian workers who were sampled in the TPHS $(p=0.013)$ and Australian workers in the NSMHWB survey $(p=0.002)$. Prevalence estimates of high psychological distress for women in the population surveys were not statistically different $(p>0.05)$ to those obtained by the researcher survey but they had higher average percentages than those calculated for men.

Within the 16 to 24 year age-group in men the differences in the TSS surveys are also pronounced $(18.7 \%$ [ref] for the researcher survey and 23.7\% [p =0.002] for the employer survey) when compared with both the TPHS $(7.1 \%, \mathrm{p}=0.132)$ and the NSMHWB $(6.2 \%$, $\mathrm{p}<0.001)$. Prevalence percentages for the employer survey were elevated across all male age-groups. For the TSS surveys, the prevalence of high psychological distress in the 16 to 24 year and 25 to 34 year women's age-groups also appeared higher than in the population surveys, with these elevations being consistent for all age-groups in the employer survey.

\section{Correlates of high psychological distress in the public sector workforce Sample characteristics}

For the researcher survey, the average age of respondents was 45 years and 67\% were female (see Supplementary File Table 1A, which shows respondent characteristics for the Partnering Healthy@Work 2010 survey). Most respondents were married (77\%), had received education up to Year 10 (54\%), were permanently employed (90\%), fulltime (61\%) employees working regular schedules (81\%), Monday to Friday (57\%). On average, respondents had public sector tenure of 12 years, worked 38 hours a week 
Table 2 Prevalence (\%) of high psychological distress ${ }^{1}$ by age and sex reported in surveys of Tasmanian and Australian employees

\begin{tabular}{|c|c|c|c|c|c|c|c|c|}
\hline \multirow[b]{2}{*}{ Age group (years) } & \multicolumn{4}{|c|}{ Men\%(N2) } & \multicolumn{4}{|c|}{ Women\%(N) } \\
\hline & PH@W 2010³ & $\mathrm{H} @ \mathrm{~W} 2009^{4}$ & TPHS $2009^{5}$ & NSMHWB $2007^{6}$ & PH@W 2010 & H@W 2009 & TPHS 2009 & NSMHWB 2007 \\
\hline $16-24$ & $18.7(16)$ & $23.7(131)$ & $7.1(84)$ & $6.2(512)$ & $16.7(64)$ & 23.7 (329) & $11.1(80)$ & $11.7(564)$ \\
\hline $25-34$ & $7.4(103)$ & 17.3 (394) & $6.7(177)$ & $9.1(467)$ & $16.4(337)$ & 22.7 (1001) & $9.8(256)$ & $14.8(544)$ \\
\hline $35-44$ & $11.8(222)$ & $17.0(695)$ & $7.4(323)$ & $6.5(687)$ & $13.2(551)$ & $18.1(1329)$ & $11.4(471)$ & 10.7 (674) \\
\hline $45-54$ & 11.5 (373) & $15.6(801)$ & $7.8(392)$ & $8.8(483)$ & $10.3(956)$ & $16.1(1871)$ & $10.1(586)$ & $10.8(555)$ \\
\hline $55-64$ & 7.1 (219) & $12.0(417)$ & $7.5(278)$ & $4.2(396)$ & $6.7(477)$ & $14.8(856)$ & $10.1(353)$ & 7.7 (379) \\
\hline $65+$ & $0.0(15)$ & $20.0(25)$ & $2.5(80)$ & $3.4(153)$ & $3.8(27)$ & $11.4(35)$ & $9.4(52)$ & $7.6(85)$ \\
\hline Total & $10.2(948)$ & $16.1(2463)$ & $7.1(1334)$ & $6.8(2698)$ & $11.6(2412)$ & $18.0(5421)$ & 10.4 (1798) & $11.2(2801)$ \\
\hline$p^{7}$ & ref & $<0.001$ & 0.013 & 0.002 & ref & $<0.001$ & 0.217 & 0.651 \\
\hline
\end{tabular}

${ }^{1}$ Prevalence was measured using the K10 and dichotomized as 'high' versus 'low' distress with K10 scores $\geq 22$ being rated as 'high'.

${ }^{2} \mathrm{~N}$, total number of respondents by category.

${ }^{3}$ Partnering Healthy@Work 2010, researcher-initiated survey of Tasmanian State Service employees (weighted).

${ }^{4}$ Healthy@Work survey 2009, employer-initiated survey of Tasmanian State Service employees (unweighted).

${ }^{5}$ Tasmanian Population Health Survey 2009, population normative data of Tasmanian workers (weighted).

${ }^{6}$ National Survey of Mental Health and Well-Being 2007, population normative data of Australian workers (weighted).

${ }^{7} \mathrm{p}$-value for the differences between total prevalence of psychological distress in the survey, relative to PH@W 2010.

and received an annual salary of $\mathrm{A} \$ 66,236$. The weighting process showed that the respondents were more likely than non-respondents to be older, female, of longer tenure, fulltime employees, and to have worked within specific government departments.

\section{Univariable correlates of high psychological distress}

Men and women showed many similar univariable correlates for high psychological distress that were statistically significant $(\mathrm{p}<0.05)$ (Table 3$)$. Using the parameters described in the Methods section, marital status, state service tenure, health behaviours, preferred hours and ERI were selected for subsequent model building across both sexes. Although age was only significantly associated with distress for women, it was included in the men's model due to its clinical importance. For men, a unique association was apparent for employment category and employment condition. Occupation, annual salary and department tenure were uniquely associated with high psychological distress among women. Furthermore, women had a significant association for both 'less hours' and 'more hours' in the preferred hours category whereas men only met the inclusion criterion for the 'less hours' category. For men, state service tenure was added at the conclusion of preliminary main effects modelling [34].

The variables contained in the fully adjusted model for men (Table 4) were classified as acceptably discriminating $(\mathrm{ROC}=0.77)$ were age, marital status, employment category, state service tenure, BMI, alcohol use, daily smoking, and perceptions of high-effort and low-reward. This set of variables provided the best discrimination between high and low/moderate psychological distress ( $\mathrm{ROC}=.76)$, with independent associations being found for younger age, fixed-term/casual employment and the upper tertile of ERI. Weighted population estimates of high distress prevalence by ERI tertiles for men were 5.8\% (lower), 5.3\% (middle) and 20.5\% (upper) respectively. A 3-fold increase in prevalence of psychological distress was evident between the highest and lowest ERI categories in the resultant model.

Among women, the set of variables providing the best discrimination between high and low/moderate psychological distress $(\mathrm{ROC}=0.75)$ were age, marital status, state service tenure BMI, alcohol use, daily smoking, fruit and vegetable intake and ERI were included in the model. Independent associations with high distress were found in the fully adjusted model for women who were younger, unmarried, and in the upper tertile of ERI (Table 4). Weighted population estimates of high distress prevalence by ERI tertile for women were $4.7 \%$ (lower), $7.2 \%$ (middle) and $22.0 \%$ (upper) respectively.

Weighted population estimates of high distress prevalence by ERI tertile for women were similar to those for men being 4.7\% (lower), 7.2\% (middle) and 22.0\% (upper) respectively. A 5-fold increase in psychological distress prevalence was identified in the highest versus lowest ERI categories.

\section{Discussion}

In this study we compared the self-reported prevalence of high psychological distress between two surveys of a public sector workforce and then with population normative worker surveys using the same K10 brief screening measure. We examined whether there were differences in the results obtained from employer and researcher approaches to data collection and we also investigated the socio-demographic, health and work correlates of high psychological distress 
Table 3 Univariable logistic regression analysis

\begin{tabular}{|c|c|c|c|c|}
\hline Variables & $\begin{array}{c}\text { Men } \\
\mathrm{PR}^{1}(95 \% \mathrm{Cl})\end{array}$ & $p$ & $\begin{array}{c}\text { Women } \\
\text { PR }(95 \% \mathrm{Cl})\end{array}$ & $p$ \\
\hline Age (years) continuous & $0.99(0.98-1.01)$ & 0.355 & $0.97(0.97-0.98)$ & $<0.001$ \\
\hline $16-24$ & 1.00 & - & 1.00 & - \\
\hline $25-34$ & $0.40(0.12-1.35)$ & 0.139 & $0.98(.053-1.83)$ & 0.959 \\
\hline $35-44$ & $0.63(0.21-1.87)$ & 0.406 & $0.79(0.43-1.45)$ & 0.446 \\
\hline $45-54$ & $0.62(0.21-1.78)$ & 0.372 & $0.62(0.34-1.13)$ & 0.116 \\
\hline $55-64$ & $0.38(0.12-1.18)$ & 0.095 & $0.40(0.21-0.78)$ & 0.007 \\
\hline $65+$ & Insufficient cases & 0.000 & $0.23(0.03-1.70)$ & 0.150 \\
\hline \multicolumn{5}{|l|}{ Marital Status } \\
\hline Not married & $2.00(1.32-3.05)$ & 0.001 & $1.41(1.10-1.79)$ & .006 \\
\hline Married/Defacto & 1.00 & - & 1.00 & - \\
\hline \multicolumn{5}{|l|}{ Occupation } \\
\hline Blue Collar & $1.15(0.62-2.13)$ & 0.668 & $1.24(0.88-1.74)$ & 0.227 \\
\hline Admin & $0.94(0.54-1.62)$ & 0.815 & $1.41(1.05-1.91)$ & 0.023 \\
\hline Service & 1.00 & - & 1.00 & - \\
\hline Professional & $1.55(0.76-3.13)$ & 0.228 & $1.29(0.60-2.80)$ & 0.517 \\
\hline Manager & $0.85(0.49-1.46)$ & 0.553 & $1.35(0.92-1.96)$ & 0.123 \\
\hline Annual Salary & $1.01(0.97-1.06)$ & 0.638 & $0.94(0.88-1.00)$ & 0.044 \\
\hline \multicolumn{5}{|l|}{ Education } \\
\hline Up to Year 10 & $0.63(0.26-1.53)$ & 0.308 & $0.92(0.65-1.31)$ & 0.653 \\
\hline Up to Year $12 /$ certificate & $1.22(0.82-1.83)$ & 0.322 & $1.02(0.80-1.33)$ & 0.826 \\
\hline Post School & 1.00 & - & 1.00 & - \\
\hline \multicolumn{5}{|l|}{ Job Classification } \\
\hline Bands 1-3 & $0.96(0.58-1.59)$ & 0.872 & $0.92(0.72-1.17)$ & 0.484 \\
\hline Bands 4-6 & $0.97(0.51-1.85)$ & 0.930 & $0.86(0.55-1.36)$ & 0.518 \\
\hline Bands 7-8 & $1.32(0.64-2.72)$ & 0.444 & $0.56(0.21-1.48)$ & 0.244 \\
\hline Bands 9-10 & 1.00 & - & 1.00 & - \\
\hline \multicolumn{5}{|l|}{ Employment Category } \\
\hline Fixed Term/ Casual & $1.77(1.10-2.86)$ & 0.018 & $1.18(0.79-1.77)$ & 0.427 \\
\hline Permanent & 1.00 & - & 1.00 & - \\
\hline \multicolumn{5}{|l|}{ Employment Condition } \\
\hline Part Time & $1.41(0.88-2.26)$ & .0156 & $0.90(0.72-1.13)$ & 0.351 \\
\hline Full Time & 1.00 & - & 1.00 & - \\
\hline \multicolumn{5}{|l|}{ Tenure } \\
\hline State Service & $0.99(0.97-1.00)$ & 0.119 & $0.98(0.97-0.99)$ & $<0.001$ \\
\hline Agency & $0.99(0.97-1.01)$ & 0.285 & $0.98(0.96-1.00)$ & 0.051 \\
\hline \multicolumn{5}{|l|}{ Days worked } \\
\hline Days Vary Weekly & $0.83(0.47-1.48)$ & 0.534 & $1.12(0.82-1.53)$ & 0.463 \\
\hline Other & $1.48(0.89-2.44)$ & 0.129 & $0.85(0.65-1.11)$ & 0.235 \\
\hline Mon to Fri & 1.00 & - & 1.00 & - \\
\hline \multicolumn{5}{|l|}{ Schedule worked } \\
\hline Regular day & $1.06(0.65-1.72)$ & 0.812 & $0.89(0.66-1.19)$ & 0.421 \\
\hline Other types & 1.00 & - & 1.00 & - \\
\hline Hours worked & $1.00(0.98-1.02)$ & 0.881 & $1.00(1.00-1.01)$ & 0.422 \\
\hline
\end{tabular}


Table 3 Univariable logistic regression analysis (Continued)

\begin{tabular}{|c|c|c|c|c|}
\hline \multicolumn{5}{|l|}{ Preferred hours } \\
\hline Less hours & $1.49(1.00-2.22)$ & .052 & $1.39(1.10-1.76)$ & 0.006 \\
\hline Same hours & 1.00 & - & 1.00 & - \\
\hline More hours & $1.26(0.48-3.32)$ & 0.635 & $1.56(1.01-2.42)$ & 0.047 \\
\hline General Health² & $1.01(0.97-1.06)$ & 0.661 & $0.99(0.98-1.01)$ & 0.489 \\
\hline BMI (per unit) & $1.05(1.01-1.08)$ & 0.010 & $1.02(1.00-1.05)$ & 0.038 \\
\hline \multicolumn{5}{|l|}{ Alcohol Intake } \\
\hline High Risk & $1.60(1.05-2.44)$ & 0.030 & $1.61(1.21-2.13)$ & 0.001 \\
\hline Low Risk & 1.00 & - & 1.00 & - \\
\hline \multicolumn{5}{|l|}{ Fruit \& Veg Intake } \\
\hline Inadequate & $1.41(0.96-2.08)$ & 0.079 & $1.46(1.16-1.83)$ & 0.001 \\
\hline Adequate & 1.00 & - & 1.00 & - \\
\hline \multicolumn{5}{|l|}{ Smoker } \\
\hline Daily Smoker & $1.89(0.99-3.61)$ & 0.053 & $1.36(0.94-1.97)$ & 0.105 \\
\hline All Others & 1.00 & - & 1.00 & - \\
\hline \multicolumn{5}{|l|}{ Physical Activity ${ }^{3}$} \\
\hline Lower & $1.30(0.78-2.18)$ & 0.318 & $0.89(0.66-1.20)$ & 0.442 \\
\hline Middle & $1.92(1.18-3.11)$ & 0.008 & $1.23(0.94-1.61)$ & 0.134 \\
\hline Upper & 1.00 & & 1.00 & - \\
\hline \multicolumn{5}{|l|}{ ERI tertiles ${ }^{4}$} \\
\hline Lower & 1.00 & - & 1.00 & - \\
\hline Middle & $1.02(0.53-1.96)$ & 0.950 & $1.53(1.00-2.35)$ & 0.051 \\
\hline Upper & $3.54(2.10-5.97)$ & $<0.001$ & $4.59(3.20-6.60)$ & $<0.001$ \\
\hline
\end{tabular}

For both sexes, we found that the prevalence of high psychological distress was greater in the employer survey when it was referenced to the researcher survey. This higher prevalence was observed across all age-groups for the employer survey. When the researcher survey was compared with population norms for workers, prevalence of high distress was greater for men but not women. It is interesting that the women's researcher and population surveys showed strong consistency in prevalence estimates despite their differing modes of data collection (telephone, paper-pencil and interview) and arguably dissimilar workforces.

Age-group differences in prevalence were also identified when comparing the public sector and population surveys, particularly with the youngest male and female age-groups. Psychological distress has been found to be more prevalent among younger people and tends to decrease as age increases [24]. Jorm and colleagues [36] found that problems such as job threats, personal problems and ending relationships were most prominent among younger age groups. Moreover, early working life coincides with a potentially stressful major developmental stage as adolescents move into adulthood and have to cope with associated adult responsibilities [37]. Recent papers have advocated the need to generally target younger workers with mental health promotion strategies [38,39] so although the age-group differences evident in this study are not conclusive, our results are in a direction that is consistent with other research.

Despite previous validation of the online K10 as a screener for depression [40], in this study administration of the K10 by an employer to a volunteer sample of employees appears to have overestimated prevalence. Screening is an important component of prevention and treatment efforts [41] but guidance on interpretation is needed to prevent inaccurate conclusions about the prevalence of distress or where preventive efforts should be targeted. Furthermore, as has been found elsewhere [3], age and sex data make a relatively limited contribution by themselves to our understanding of the drivers of 
Table 4 Sequential log binomial regression models

\begin{tabular}{|c|c|c|c|c|c|c|}
\hline \multirow[b]{2}{*}{ Variables } & \multicolumn{3}{|c|}{ Men } & \multicolumn{3}{|c|}{ Women } \\
\hline & $\mathrm{PR}^{1}$ & $95 \% \mathrm{Cl}^{2}$ & $p$ & PR & $95 \% \mathrm{Cl}$ & $p$ \\
\hline \multicolumn{7}{|l|}{ Demographic variables } \\
\hline Age & 0.97 & $0.94-1.00$ & 0.016 & 0.97 & $0.95-0.99$ & 0.007 \\
\hline Marital status & 1.31 & $0.70-2.48$ & 0.388 & 1.44 & $1.01-2.05$ & 0.048 \\
\hline \multicolumn{7}{|l|}{ Job characteristics } \\
\hline Employment category & 2.61 & $1.25-5.47$ & 0.011 & - & - & - \\
\hline State Service tenure & 0.98 & $0.95-1.01$ & 0.147 & 0.99 & $0.96-1.01$ & 0.240 \\
\hline \multicolumn{7}{|l|}{ Health-risk behaviours } \\
\hline BMl & 1.03 & $0.97-1.09$ & 0.396 & 1.02 & $0.99-1.05$ & 0.143 \\
\hline Risky alcohol & 1.24 & $0.68-2.26$ & 0.479 & 1.17 & $0.79-1.71$ & 0.438 \\
\hline Daily smoker & 1.86 & $0.89-3.92$ & 0.101 & 1.35 & $0.88-2.09$ & 0.168 \\
\hline Inadequate fruit and vegetable intake & - & - & - & 1.27 & $0.88-1.80$ & 0.200 \\
\hline \multicolumn{7}{|l|}{ Psychosocial factors } \\
\hline \multicolumn{7}{|l|}{$\left.E R\right|^{2}$} \\
\hline Middle & 0.79 & $0.30-2.05$ & 0.624 & 1.52 & $0.75-3.11$ & 0.246 \\
\hline Upper & 3.37 & $1.52-7.47$ & 0.003 & 5.28 & $2.91-9.75$ & $<0.001$ \\
\hline$R O C^{3}$ & & .7659 & & & .7559 & \\
\hline
\end{tabular}

Correlates of high psychological distress for men and women participating in the Partnering Healthy@Work 2010 survey.

${ }^{1} \mathrm{PR}$, Prevalence Ratio; $\mathrm{Cl}$, Confidence Interval.

${ }^{2}$ ERI, Effort-Reward Imbalance tertiles.

${ }^{3} \mathrm{ROC}$, Area under the Receiver Operating Characteristics curve

- Models for men and women were calculated separately.

- Reference categories: married or defacto, permanent employment, not risky alcohol, not daily smoker, ERI lower tertile. Age, state service tenure and BMI are continuous variables.

- Omitted categories, designated with a ' ${ }^{\prime}$ identify that the variable did not make a contribution $(p>0.05)$ to the ROC.

worker psychological distress within organisations. It was a necessary step in this research setting to assess whether high distress, as measured by the K10, was associated with expected correlates. Modelling was necessary to investigate this issue.

The logistic modelling results showed that the best set of variables to predict high psychological distress in both men and women were age, marital status, state service tenure, BMI, alcohol use, daily smoking and ERI, although not all included variables were independently associated with distress. For men, employment category (permanent vs. fixed-term/ casual) was also important, while for women fruit and vegetable intake contributed to model discrimination but was not itself independently associated with distress.

In the men's fully adjusted model, high psychological distress was independently associated with lower age, fixed term or casual employment and the upper tertile of ERI. High distress prevalence was twice as likely for men in fixed term or casual employment and three times more likely if they were experiencing high effort reward imbalance. It has historically been argued that rationalization of the public sector has contributed to higher levels of psychological distress [9]. Although this public service had not commenced rationalization at the time of the surveys, lag effects of historical organisational changes could be considered. Men have also been found to be at higher risk of psychological distress in the face of job insecurity [42] which can be assessed through employment category and ERI variables. Nevertheless, it is also possible that workers with poorer mental health are more likely to hold precarious temporary employment [43]. Further investigation is needed to establish the direction of effect and factors influencing men's mental health in this public service.

For the women's fully adjusted model, younger age, being unmarried, and high ERI were independently associated with high psychological distress, with ERI making the major contribution. The results estimate that the prevalence of distress among those in the upper tertile of ERI was $20 \%$ for men and $22 \%$ for women. This finding, combined with longitudinal evidence of association [44], suggests that if attention is given to addressing the risk of effort-reward imbalance, there may be a related reduction in the risk of high psychological distress in the workplace. The reasons for the strength of the ERI contribution to the models are an area for further investigation. As an example, Tsutsumi and Kawakami [45] have proposed that extrinsic efforts (e.g. overtime, workload) and rewards (e.g. praise, development opportunities) can 
be a focus of organisational interventions to overcome imbalance. Few interventions have yet been developed based on improving ERI but early attempts show promise (e.g. [44]).

Overall, the models presented here suggest priorities for mental health intervention would include men in fixed-term or casual employment, younger workers and those experiencing high Effort-Reward Imbalance. Responses based on randomly sampled, weighted data identified correlates of high psychological distress that are reasonably consistent with other international studies, and provided direction as to sub-populations needing targeting through workplace mental health promotion strategies. These findings provide support for use of the K10 as a brief screening measure of psychological distress within an organisational context, providing appropriate guidance on interpretation is available.

\section{Limitations}

These study implications need to be examined in view of several limitations. First, participation rates were below $30 \%$ for both of the public sector surveys, though these rates are typical for the field [3]. A key strength of this study is the use of weighting procedures to help control for response bias in the researcher survey. In comparison, the employer survey was unweighted and may not have provided a reliable indication of psychological distress prevalence in this public sector workforce. Second, it is possible that the differences in survey data collection methods are biasing the results. However, Mealing and colleagues have argued against this position [46], finding that relative risk estimates were consistent for studies of the same population with different methods of data collection, response rates and sampling methods as long as survey questions were the same. A recent study has also found no significant differences between response rates, or types of responses to questions whether surveys were perceived to be anonymous or not [47]. We acknowledge that the population studies we have used as comparators may have underestimated the prevalence of psychological distress due to non-response bias [18]. However, we required points of adjudication because the workforce survey results were conflicting and these norms were the best estimates available. Third, this study is cross-sectional and the direction of relationships cannot be established. Kolstadt and coworkers [48] have also suggested that reporting bias can inflate associations between self-reported job-strain and depression, and a work unit analysis may show weaker associations than those found here. Finally, there is room for improvement in the types of measures applied in this study. For instance, our study used the socioeconomic variable 'annual salary' as a proxy measure for income, which may be an underestimate for occupations with allowances and overtime (e.g. police, nurses). Future measurement of additional contextual measures also seems likely to strengthen our understanding of the variables discriminating high from low psychological distress in public sector workforces.

\section{Implications for practice: how should these findings be used?}

After the employer survey was conducted, this public sector organisation acted on the findings by implementing a mental health promotion strategy that was predominantly focused upon general education about mental health. The impact of this approach is yet to be determined as follow-up data collection is underway, but this study suggests a greater reduction in risk may be obtained if specific sub-populations with poor mental health (i.e. men and younger workers) and people with high effort-reward imbalance are targeted. Anonymous, volunteer surveys of worker mental health may be resource efficient and promote participation but this example suggests they may not advance management decision-making. Health Risk Appraisals for risk reduction rely on valid assessments of health outcomes. Inaccurate results could lead to expensive resource allocation that is ineffective in reducing the risk of poor mental health in the workplace. In addition, mental health screening may also only be of limited use without the collection of at least some of the known important correlates (e.g. individual characteristics, psychosocial factors) to allow specific targeting of interventions. Clinicians have an important role in educating employers about mental health screening and giving advice on health survey interpretation.

\section{Conclusions}

Understanding the nature of workplace-based risks associated with poor mental health and addressing these risk factors is a pressing public health issue. Depression and anxiety screening forms part of a response to this challenge but this study showed that screening using typical employer survey methods with a validated measure could overestimate prevalence. Depression and anxiety screening should be promoted to employers and employees but guidance is needed on interpretation. In identifying priority groups for intervention, perceived work stress and a fixed term/casual employment contract may be particularly important among men.

\section{Abbreviations}

K10: Kessler-10; ERI: Effort reward imbalance.

\section{Competing interests}

The authors declare they have no competing interests.

\section{Authors' contributions}

This work was competed as part of $L J$ 's PhD, supervised by KS, AV and AM. $\mathrm{LJ}$ and $\mathrm{KS}$ planned the design of the manuscript, KS, AV, AM, BT and RT 
negotiated with the organisations and organised the data collection, $L J$ and $\mathrm{PO}$ analysed the data, $\mathrm{L}$ wrote the first draft of the manuscript and $\mathrm{KS}, \mathrm{AV}$, A M, RT and BT critically commented it and participated in the editing of the final version. All authors have approved the final version of the manuscript.

\section{Acknowledgements}

This work was undertaken at the Menzies Research Institute Tasmania, Hobart, Australia. The authors were supported in their work by a National Health and Medical Research Council (NHMRC) Partnership Grant (ID 544954) and funding and in-kind support from the Tasmanian Government. $L$ was supported by an Australian Post-Graduate Award Scholarship, KS was supported by an Australian Research Council Future Fellowship (FT0991524), and AV by a NHMRC Research Fellowship. Funding bodies played no role in the study design, collection, analysis or interpretation of data, writing of the report or decision to submit this article for publication. We are very grateful to the study participants for their time and effort. We also thank Ms Helen Galea for her assistance in data management and Mrs Doreen Bate for her administrative management of the project.

\section{Author details}

${ }^{1}$ Menzies Research Institute Tasmania, University of Tasmania, Hobart, Tasmania, Australia. ${ }^{2}$ Tasmanian School of Business and Economics, University of Tasmania, Hobart, Tasmania, Australia. ${ }^{3}$ Department of Health and Human Services, Tasmanian State Government, Hobart, Tasmania, Australia.

${ }^{4}$ Department of Premier and Cabinet, Tasmanian State Government, Hobart, Tasmania, Australia.

Received: 26 June 2013 Accepted: 4 February 2014

Published: 6 February 2014

\section{References}

1. Kessler R, Aguilar-Gaxiola S, Alonso J, Chatterji S, Lee S, Ormel J, Ustun TB, Wang PS: The global burden of mental disorders: An update from the WHO World Mental Health (WMH) Surveys. Epidemiol Psichiatr Soc 2009, 18(1):23-33.

2. Hees $\mathrm{HL}$, Koeter MW, Schene $\mathrm{AH}$ : Longitudinal relationship between depressive symptoms and work outcomes in clinically treated patients with long-term sickness absence related to major depressive disorder. $J$ Affect Disord 2013, 148(2-3):272-277.

3. Hilton MF, Whiteford HA, Sheridan JS, Cleary CM, Chant DC, Wang PS, Kessler RC: The prevalence of psychological distress in employees and associated occupational risk factors. J Occup Environ Med 2008, 50(7):746-757.

4. Myette TL: Research on depression in the workplace: where do we go from here? J Occup Environ Med 2008, 50(4):492-500.

5. Schoenbach VJ, Wagner EH, Beery WL: Health risk appraisal: review of evidence for effectiveness. Health Serv Res 1987, 22(4):553-580

6. Soler RE, Leeks KD, Razi S, Hopkins DP, Griffith M, Aten A, Chattopadhyay SK, Smith SC, Habarta N, Goetzel RZ, et al: A Systematic Review of Selected Interventions for Worksite Health Promotion The Assessment of Health Risks with Feedback. Am J Prev Med 2010, 38(2):S237-S262.

7. Mellor N, Smith P, Mackay C, Palferman D: The "Management Standards" for stress in large organizations. Int J Workplace Health Mana 2013 6(1):4-17.

8. Cleary CM, Hilton MF, Sheridan J, Whiteford HA: Corporate barriers preventing the initiation of mental health programs. J Occup Health Saf - Austr N Z 2008, 24(6):507-517.

9. McHugh M: Rationalization as a key stressor for public sector employees: an organizational case study. Occup Med (Lond) 1998, 48(2):103-112.

10. Bell R, Britton A, Brunner E, Chandola T, Ferrie J, Harris M, Head J, Marmot M, Mein G, Stafford M: Work, Stress and Health: The Whitehall II Study. London: Public and Commercial Services Union on behalf of the Council of Services Unions/ Cabinet Office; 2004

11. Hood C: A public management for all seasons. Public Adm 2007 69(1):3-19.

12. Bamberger SG, Vinding AL, Larsen $A$, Nielsen $P$, Fonager $K$, Nielsen RN, Ryom P, Omland O: Impact of organisational change on mental health: a systematic review. Occup Environ Med 2012, 69(8):592-598.

13. Noblet A, Lamontagne AD: The role of workplace health promotion in addressing job stress. Health Promot Int 2006, 21(4):346-353.

14. Heponiemi T, Elovainio M, Pentti J, Virtanen M, Westerlund $H$, Virtanen $P$, Oksanen T, Kivimaki M, Vahtera J: Association of Contractual and
Subjective Job Insecurity With Sickness Presenteeism Among Public Sector Employees. J Occup Environ Med 2010, 52(8):830-835.

15. Vahtera J, Kivimaki M, Pentti J: Effect of organisational downsizing on health of employees. Lancet 1997, 350(9085):1124-1128.

16. EU-OHSA: Drivers and Barriers for Psychosocial Risk Management: An Analysis of the Findings of the European Survey of Enterprises on New and Emerging Risks (ESENER). Luxembourg: Publications Office of the European Union; 2012.

17. United States Bureau of Labor Statistics: Table 1. Incidence rates of nonfatal occupational injuries and illnesses by case type and ownership. Washington DC; 2011 [www.bls-gov/news.release/osh/t01.htm]

18. Knudsen AK, Hotopf M, Skogen JC, Overland S, Mykletun A: The health status of nonparticipants in a population-based health study: the Hordaland Health Study. Am J Epidemiol 2010, 172(11):1306-1314.

19. Kessler RC, Andrews G, Colpe $\sqcup$, Hiripi E, Mroczek DK, Normand SL, Walters EE, Zaslavsky AM: Short screening scales to monitor population prevalences and trends in non-specific psychological distress. Psychol Med 2002, 32(6):959-976.

20. Furukawa TA, Kessler RC, Slade T, Andrews G: The performance of the K6 and K10 screening scales for psychological distress in the Australian National Survey of Mental Health and Well-Being. Psychol Med 2003, 33(2):357-362.

21. Hofler M, Pfister $H$, Lieb R, Wittchen $H$ : The use of weights to account for non-response and drop-out. Soc Psychiatry Psychiatr Epidemiol 2005, 40:291-299.

22. Australian Bureau of Statistics: National Survey of Mental Health and Wellbeing: Confidentialised Unit Record File (Cat No. 4326). Canberra: ABS; 2007.

23. Challice G: The Tasmanian Population Health Survey 2009. North Melbourne Victoria: The Social Research Centre; 2009.

24. Phongsavan P, Chey T, Bauman A, Brooks R, Silove D: Social capital, socioeconomic status and psychological distress among Australian adults. Soc Sci Med 2006, 63(10):2546-2561

25. Sanderson K, Andrews G: The SF-12 in the Australian population: Crossvalidation of item selection. Aust N Z J Public Health 2002, 26(4):343-345.

26. Paul SL, Blizzard L, Patton GC, Dwyer T, Venn A: Parental smoking and smoking experimentation in childhood increase the risk of being a smoker 20 years later: the Childhood Determinants of Adult Health Study. Addiction 2008, 103(5):846-853.

27. McNaughton SA, Ball K, Crawford D, Mishra GD: An index of diet and eating patterns is a valid measure of diet quality in an Australian population. J Nutr 2008, 138(1):86-93.

28. Bush K, Kivlahan DR, McDonell MB, Fihn SD, Bradley KA, Project ACQI The AUDIT alcohol consumption questions (AUDIT-C) - An effective brief screening test for problem drinking. Arch Intern Med 1998, 158(16):1789-1795.

29. National Health and Medical Research Council: The Australian guidelines to reduce health risk from drinking alcohol. Canberra: Commonwealth of Australia; 2009

30. Alonso J, Vilagut G, Chatterji S, Heeringa S, Schoenbaum M, Bedirhan Üstün T, Rojas-Farreras S, Angermeyer M, Bromet E, Bruffaerts R, et al: Including information about co-morbidity in estimates of disease burden: Results from the World Health Organization World Mental Health Surveys. Psychol Med 2011, 41(4):873-886.

31. Siegrist J, Starke D, Chandola T, Godin I, Marmot M, Niedhammer I, Peter R: The measurement of effort-reward imbalance at work: European comparisons. Soc Sci Med 2004, 58(8):1483-1499.

32. Kessler RC: Epidemiology of women and depression. J Affect Disord 2003, 74(1):5-13.

33. Hellerstedt $W L$, Jeffery RW: The association of job strain and health behaviours in men and women. Int J Epidemiol 1997, 26(3):575-583.

34. Hosmer DW, Lemeshow SL: Applied Logistic Regression. 2nd edition. New York: John Wiley \& Sons; 2000.

35. Zou GY: A modified Poisson regression approach to prospective studies with binary data. Am J Epidemiol 2004, 159(7):702-706.

36. Jorm AF, Windsor TD, Dear KBG, Anstey KJ, Christensen H, Rodgers B: Age group differences in psychological distress: the role of psychosocial risk factors that vary with age. Psychol Med 2005, 35(9):1253-1263.

37. Drapeau A, Marchand A, Beaulieu-Prevost D: Epidemiology of Psychological Distress. Montreal; 2011 [http://www.intechopen.com/source/pdfs/25512/ InTech-Epidemiology_of_psychological_distress.pdf] 
38. Dietrich S, Deckert S, Ceynowa M, Hegerl U, Stengler K: Depression in the workplace: a systematic review of evidence-based prevention strategies. Int Arch Occup Environ Health 2011, 85(1):1-11.

39. LaMontagne AD, D'Souza RM, Shann CB: Socio-demographic and work setting correlates of poor mental health in a population sample of working Victorians: application in evidence-based intervention priority setting. Int J Ment Health Promot 2012, 14(2):109-122.

40. Donker T, van Straten A, Marks I, Cuijpers P: Brief self-rated screening for depression on the Internet. J Affect Disord 2010, 122(3):253-259.

41. Halpin HA, McMenamin SB, Schmittdiel J, Gillies RR, Shortell SM, Rundall T, Casalino $L$ : The routine use of health risk appraisals: Results from a national study of physician organisations. Am J Health Promot 2005, 20(1):34-38

42. Murcia M, Chastang JF, Niedhammer I: Psychosocial work factors, major depressive and generalised anxiety disorders: results from the French national SIP study. J Affect Disord 2013, 146(3):319-327.

43. Wagenaar AF, Kompier MA, Houtman IL, van den Bossche SN, Taris TW: Employment contracts and health selection: unhealthy employees out and healthy employees in? Epidemiol Psichiatr Soc 2012, 54(10):1192-1200.

44. Bourbonnais R, Brisson C, Vezina M: Long-term effects of an intervention on psychosocial work factors among healthcare professionals in a hospital setting. Occup Environ Med 2011, 68(7):479-486.

45. Tsutsumi A, Kawakami N: A review of empirical studies on the model of effort-reward imbalance at work: reducing occupational stress by implementing a new theory. Soc Sci Med 2004, 59(11):2335-2359.

46. Mealing NM, Banks E, Jorm LR, Steel DG, Clements MS, Rogers KD: Investigation of relative risk estimates from studies of the same population with contrasting response rates and designs. BMC Med Res Methodol 2010, 10:26.

47. Mueller K, Straatmann T, Hattrup K, Jochum M: Effects of Personalized Versus Generic Implementation of an Intra-Organizational Online Survey on Psychological Anonymity and Response Behavior: A Field Experiment. J Bus Psychol 2012:1-13.

48. Kolstad HA, Hansen AM, Kaergaard A, Thomsen JF, Kaerlev L, Mikkelsen S, Grynderup MB, Mors O, Rugulies R, Kristensen AS, et al: Job strain and the risk of depression: is reporting biased? Am J Epidemiol 2011, 173(1):94-102.

doi:10.1186/1471-2458-14-125

Cite this article as: Jarman et al:: Prevalence and correlates of psychological distress in a large and diverse public sector workforce: baseline results from Partnering Healthy@Work. BMC Public Health 2014 14:125.

\section{Submit your next manuscript to BioMed Central and take full advantage of:}

- Convenient online submission

- Thorough peer review

- No space constraints or color figure charges

- Immediate publication on acceptance

- Inclusion in PubMed, CAS, Scopus and Google Scholar

- Research which is freely available for redistribution 